\title{
Güney Çin Denizi Sorunu Çerçevesinde Çin-Hindistan ilişkileri
}

\section{Cemre PEKCAN*}

Öz

Malakka Boğazı vasıtasıyla dünya ticareti için en önemli noktalardan biri olmasının yanı sıra zengin doğal kaynaklara sahip olan Güney Çin Denizi, başta Çin olmak üzere, burada hak iddia eden Tayvan, Vietnam, Kamboçya, Filipinler, Malezya ve Brunei arasında uzun süredir sorun olmaya devam etmektedir. Güney Çin Denizi'nin önemi nedeniyle bu sorun küresel bir boyut kazanmış ve $A B D$, Japonya gibi devletler de kendi çıkarlarını korumak amacıyla soruna müdahil olmuşlardır. Son dönemlerde ise yükselen bir güç olan Hindistan, özellikle Vietnam tarafindan, Çin'i dengelemek amacıyla soruna dahil edilmek istenmektedir. Bu bağlamda makalede; Çin-Hindistan ilişkileri ve Güney Çin Denizi'ndeki sorunun gelişimi hakkında kısa bir bilgi verildikten sonra, Güney Çin Denizi sorununa Hindistan'ın neden ve ne şekilde dahil olduğu, bu durumun bölgesel dinamikler açııından önemi ve Çin-Hindistan ilişkilerine yansımaları incelenmektedir.

Anahtar Kelimeler: Malakka Boğazı, Güney Çin Denizi, Hindistan, Çin.

\section{China-India Relations within the Framework of South China Sea Dispute}

\begin{abstract}
The South China Sea, which has rich natural resources as well as being one of the most important trade routes through the Strait of Malacca, continues to be a problem between China, Taiwan, Vietnam, Cambodia, the Philippines, Malasia and Brunei as they all claim sovereignty over some parts of the sea. The issue has gained a global dimension with the involvement of powers such as the US and Japan to protect their own interests. Recently, especially Vietnam wants to implicate India to the South China Sea issue to balance China. In this context, after giving a brief information about China-India relations and the developmet of the South China Sea problem, the article tries to analyse the reasons of India's involvement, the importance of India's involvement for regional dynamics and its effect to China-India relations.
\end{abstract}

Keywords: the Strait of Malacca, the South China Sea, India, China.

* Araştirma Görevlisi Doktor, Çanakkale Onsekiz Mart Üniversitesi, Iktisadi ve İdari Bilimler Fakültesi, Uluslararası İlişkiler Bölümü, cemrepekcan83@hotmail.com 


\section{Giriş}

Dünyanın ikinci büyük ekonomisi Çin ve beşinci büyük ekonomisi Hindistan, Asya'daki bölgesel dinamikleri belirleyen iki büyük güçtür. Bu iki köklü medeniyet arasındaki ilişki binlerce yıldır süregelmekle birlikte, günümüzde, iki ülke arasındaki çatışmalar veya işbirlikleri bölgedeki istikrar açısından büyük önem taşımaktadır.

İki ülke arasındaki en büyük problem uzun zamandır süren ve çözümü oldukça karışık olan sınır problemleridir. Öyle ki sınır problemleri 1962 yılında iki ülkeyi savaşa sürüklemiş ve 1976 yılına dek ilişkileri koparmıştır. Sınır problemleri hala devam etse de, 1976'dan sonra hızla olumlu yönde ilerleyen ilişkilerle birlikte iki ülke ekonomik anlamda giderek birbirlerine daha bağımlı hale gelmişlerdir.

Günümüzde Asya'daki en büyük problemlerden biri Güney Çin Denizi sorunudur. Güney Çin Denizi'ndeki adalar üzerinde hak iddia eden alt devlet (Çin (Tayvan), Vietnam, Kamboçya, Filipinler, Malezya ve Brunei), sorunun çözümün ilişkin çeşitli anlaşmalar imzalamış olsalar da, çeşitli ihlaller sonucu sorunlar devam etmektedir. Dünya ticaretinin neredeyse yarısının bu bölgeden geçmesi, kendi çıkarları için bölgede istikrar isteyen $A B D$ gibi diğer büyük güçlerin de soruna müdahil olmasına neden olmaktadır. Son dönemlerde Hindistan da Güney Çin Denizi sorununa müdahil olan devletlerden biridir. Kendi ekonomik çıkarlarının zarar görmesinden endişe eden Hindistan, Vietnam gibi devletlerce Çin'e karşı dengeyi sağlamak amacıyla, ortak petrol arama gibi faaliyetlerle bölgeye çekilmek istenmektedir.

Bu bağlamda çalışmada, Çin-Hindistan ilişkileri ve Güney Çin Denizi'ndeki sorunun gelişimi hakkında kısa bir bilgi verildikten sonra, Güney Çin Denizi sorununa Hindistan'ın neden ve ne şekilde dahil olduğu, bu durumun bölgesel dinamikler açısından önemi ve Çin-Hindistan ilişkilerine yansımaları incelenmektedir.

Çalışmada, konuya ilişkin bilimsel içerikli kitap ve makalelerden, dergilerden, yayınlardan ve konuyla ilgili çıkan haberlerden faydalanılmıştır.

\section{1. ÇIN-HINDISTAN ILIŞKILERINE TARIHSEL BAKIŞ}

Her ikisi de dünyadaki en eski medeniyetlerden olan Çin ve Hindistan arasındaki ilişkilerin bilinen kayıtları Han Hanedanlığı Dönemi'ne (M.Ö.206-M.S. 220) dayanmaktadır. (Arif, 2013: 130). Hindistan'ın 1947'de, Çin Halk Cumhuriyeti'nin ise 1949 'da bağımsızlığını ilan etmesiyle birlikte iki ülke bağımsız devletler olarak uluslararası sistemdeki yerlerini almışlardır.

Soğuk Savaş'ın ilk yıllarında Nehru'nun Hindistan'ı ve Mao'nun Çin'i, sömürge karşıtlığı, sosyalizm, uluslararası ilişkilerde ulusal egemenlik ve eşitlik kavramlarına bağlıık ve büyük güç politikalarından kendilerini ayıran, gelişmekte olan ülke mentalitesi konularında ortak bir davada buluşmuşlardır. (Mitchell ve Bajpaee, 2007: 152). Öyle ki, iki ülke 1954 yılında 'Barış İçinde Bir Arada Yaşamanın Beş ilkesi'ni kabul etmiştir. Hintçe Panchsheel olarak da bilinen bu beş ilke; 'her iki tarafin toprak bütünlüğüne ve egemenliğine karşııılı saygı', 'karşılıklı saldırmazlık', 'birbirinin içişlerine karışmama', 'eşitlik ve ortak fayda' ve 'barış içinde bir arada yaşama'dır. (Agreement Between India and China, 1954). Ancak tüm bu olumlu görünen gelişmelere rağmen, iki ülke arasında bazı sınır problemleri devam etmiştir. Devam eden sınır problemleriyle birlikte, Çin'in 
Tibet'i işgali sonrası 1959 'da Tibet'in ruhani lideri Dalay Lama'nın Hindistan'a kaçarak burada bir sürgünde hükümet kurması, sınır bölgesi olan Aksai Chin boyunca Çin'in bir yol inşa etmesi ve Hindistan'ın tartş̧malı bölgelere askeri karakollar kurması gibi gelişmeler, iki ülke arasında 1962 yılında bir savaşa neden olmuştur. (Mitchell ve Bajpaee, 2007: 152). Savaş sonunda Çin, sınır bölgesinde iddia ettiği yerlerde hakimiyetini kurarak ateşkes ilan etmiş, her hangi bir toprağı fethetmeyerek, yalnızca McMahon Hatt'nın ${ }^{1}$ güneyindeki bölge üzerinde hak iddiasına devam etmiştir. (Kissinger, 2012:191).

Görüldüğü gibi, 1950'lerde Çin ve Hindistan arasındaki olumlu ve dostane ilişkiler, 1962 savaşıyla büyük zarar görmüş ve bu durum 1970 'leri ortalarına dek devam etmiştir. Bu dönemde Pakistan'la ilişkilerini geliştiren Çin'in karşısında, Hindistan da Sovyetlerle ilişkilerini geliştirme yoluna gitmiştir. 1972'de Çin'i ziyaret eden ABD Başkanı Nixon ve sonrasında gelen Çin-ABD normalleşme süreciyle birlikte, bir tarafta Çin-ABD-Pakistan, diğer tarafta Hindistan ve Sovyetler Birliği, başta Asya olmak üzere tüm dünyada bir tehdit oluşturmuşlardır. (Cheng, 2010:3).

İki ülke arasında yaşanan tüm gerilimlerden sonra, diplomatik ilişkiler yeniden 1976 yılında başlamıştı. Diplomatik ilişkilerin yeniden kurulmasıyla birlikte iki ülke ilişkileri ivme kazanmıştr. 1992'de Hindistan Cumhurbaşkanı R. Venkataraman Çin'e bir ziyarette bulunmuş, karşılığında 1996'da Çin Cumhurbaşkanı Jiang Zemin, Hindistan'ı ziyaret etmiştir. Bu ziyaretler, iki ülke arasında devlet başkanları düzeyindeki ilk ziyaretler olmuştur. (Ministry of External Affairs, 2012). Bu ziyaretler sırasında iki ülke arasında askeri, ekonomik vb. pek çok işbirliği anlaşması yapılmıştır.

1949'da Çin Halk Cumhuriyeti ilan edildikten sonra, Mao Zedong liderliğinde Çin'in ekonomisi, devlet kontrolünde ve kapalı bir ekonomiydi. Mao'nun 1976'da ölümünden sonra başa gelen Deng Xiaoping, reform ve dışa açılma olarak adlandırılan politikasıyla, Çin ekonomisinde büyük bir dönüşüme imza atmış ve yapılan reformlar sonucu Çin, ekonomik alanda büyük bir güç haline gelmeye başlamıştır. Ekonomik ilişkiler çerçevesinde, resmi olarak 1978 yılında ticarete yeniden başlayan Çin ve Hindistan, 1984 yılında aralarında 'En Çok Kayırılan Ülke Anlaşmasını' (the Most Favoured Nation Agreement) imzalamışlardır. 1994 yılında ise, iki ülke arasında çifte tarifeyi kaldırma anlaşması imzalanmıştır. (Maps of India, 2016). Aralarındaki ekonomik ilişkiler hızla gelişen Çin ve Hindistan, 2003 yılında, birbirlerine bazı ticari imtiyazlar tanıyan Bangkok Anlaşması'nı imzalamışlardır. Yine aynı yıl içerisinde, İpek Yolu vasıtasıyla açık sınır ticaretini başlatmak için girişimlerde bulunmuşlardır. (Economy Watch, 2010).

İki ülke arasındaki ticare bakıldığında, 2000'de 2,92 milyar dolar olan ticaret, 2008 yılında 51,8 milyar dolara ulaşmış ve Çin, ABD'yi geçerek, Hindistan'ın en büyük ticaret ortağı haline gelmiştir. 2009'da dünya genelindeki ekonomik kriz nedeniyle yaklaşık \%16 düşüş gösteren ticaret, 2010 yılında \%43'lük bir büyümeyle 61,74 milyar dolara ulaşmıştır. (Embassy of India, 2016). 2014 yılında ise ikili ticaret 70,25 milyar dolardır. (Embassy of India, 2016). Çin ve Hindistan arasındaki ticaret hacmi oldukça yüksek olmasına rağmen, Hindistan aleyhine giderek büyüyen ticaret açığı iki ülke arasında problem olmaya devam etmektedir. Aşağıdaki tablo, 2009-2015 yılları arasında Hindistan'ın Çin'le ticaretini ve artan ticaret açığını göstermektedir.

1 McMahon Hatt (McMahon Line); Britanya ve Tibet arasında 1914'te imzalanan Simla Sözleşmesi'nde geçen, Çin ve Hindistan arasındaki sınırı belirleyen bir hattır. 
Tablo 1. Hindistan-Çin Arasındaki Ticaret (2009-2015) (milyar dolar)

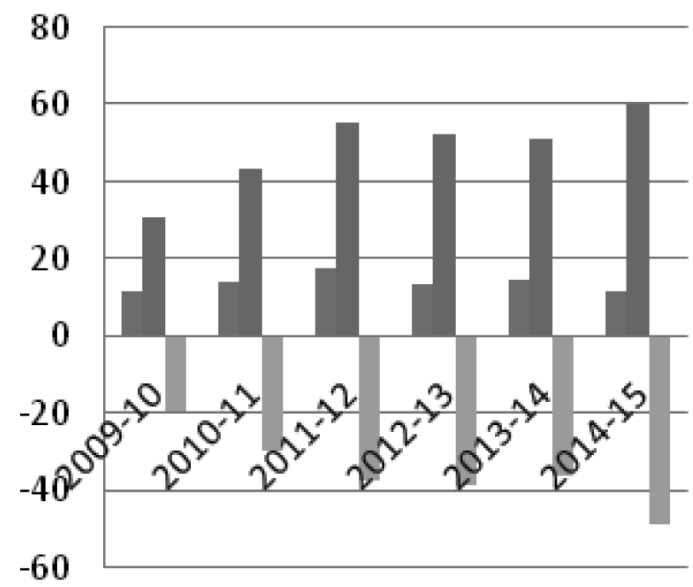

- Hindistan'ın Çin"e İhracatı

- Hindistan'ın Çin'den İthalatı

- Ticaret Hacmi

Kaynak: Ministry of Commerce, Government of India

Yukarıdaki tabloda ifade edildiği gibi, 2009-2010 yılında Hindistan aleyhine -19,206 milyar dolar olan ticaret hacmi, 2011-2012 yıllarında -37,237 milyar dolara, 2014-15'te ise $-48,438$ milyar dolara yükselmiştir. Hindistan'ın Sanayi Politikaları Bakanı Amitabh Kant, konuyla ilgili; Çin ve Hindistan arasındaki ticaret açığının uzun dönemde sürdürülebilir olmadığını, Hindistan'ın gelecek yıllarda bazı koruma önlemleri alması gerektiğini ve Çinli şirketin bunu anlamasının çok önemli olduğunu ifade etmiştir. (Panda, 2014).

Ticaret açı̆ı̆yla ilgili sorunlar devam etse de iki ülke arasındaki diplomatik ve kültürel ilişkiler, çeşitli üst düzey ziyaretler, imzalanan anlaşmalar, ortaklıklar ve kültürel değişim programlarıyla hızla devam etmektedir. 2014 yılının Eylül ayında Hindistan'ı ziyaret eden Çin Cumhurbaşkanı Xi Jinping, gelecek beş yıl içerisinde Çin'in Hindistan'daki demiryolları, sanayi parkları ve potansiyel olarak da nükleer gücüne milyarlarca dolar yatırım yapacağını ve Hindistan'ın Şangay İşbirliği Örgütü’ne tam üyeliğine destek vereceğini söylemiştir. (Burke, 2014).

Günümüzde Çin de, Hindistan da ekonomisi hızla büyüyen iki ülkedir ve bu bağlamda aralarındaki işbirliğini güçlendirmek her iki ülkenin de öncelikli hedefidir. Ancak, iki ülke arasındaki çözülemeyen sınır problemleri dönem dönem tansiyonu artırmaktadır.

Çin ve Hindistan'ın son dönemlerde rakip olduğu bir diğer konu da Güney Çin Denizi konusudur. Her ne kadar Hindistan'ın Güney Çin Denizi'ne bir sınırı bulunmasa da, ticaretinin büyük kısmını Güney Çin Denizi'ndeki Malakka Boğazı vasıtasıyla yapması nedeniyle soruna müdahil olmuştur. Bu bağlamda Güney Çin Denizi sorununun Çin ve Hindistan ilişkilerini nasıl etkilediğine geçmeden önce, bir sonraki başlıkta Güney Çin Denizi sorunu analiz edilecektir.

\section{GÜNEY ÇIN DENIZI SORUNU}

Pasifik Okyanusu'nun bir parçası olan ve büyük miktarda petrol ve doğal gaz rezervi bulundurduğuna inanılan Güney Çin Denizi'ne kıyısı olan devletler; Çin, Tayvan, Vietnam, 
Kamboçya, Filipinler, Malezya ve Brunei'dir. Petrol ve doğal gaz rezervlerinin yanı sıra, bölgenin balıkçılık açısından zenginliği ve gemi taşımacılığı için önemli bir rota olması, Güney Çin Denizi'nin önemli kılan diğer unsurlardır. Artan enerji ihtiyacı ise, bölgede uzun yıllardır süren hakimiyet iddialarında tansiyonu giderek artırmaktadır.

Malakka Boğazı vasıtasıyla dünya ticaretinin \%40'ının geçiş güzergahında olan Güney Çin Denizi'nde yukarıda adı geçen altı ülke hak iddia etmektedir. (Tayvan, Çin'in bir parçası olduğundan ve iddiaları ortak olduğundan ayrıca ele alınmayacaktır). Çin haricindeki ülkeler, çeşitli kayalıkları ve küçük adacıkları içeren denizin belli bölgelerinde hak iddia ederken Çin, neredeyse denizin tamamında hak iddia etmekte ve bunu Dokuz Çizgi Hatt (nine-dotted line/ U-shape line/ nine-dash map- 南海九段线, nánhăi jiǔduàn xiàn) adı verdiği resmi belgelere dayandırmaktadır. (Broderick, 2015: 1).

Çin'in, Tayvan'la birlikte hak iddia ettiği U şeklindeki bu Dokuz Çizgi Hatt, Güney Çin Denizi'nin neredeyse tamamını kapsamaktadır. Çin'in, bu Dokuz Çizgi Hattı́nın tamamında mı yoksa daha az bir kısımda mı hak iddia ettiği hala belirsizliğini korusa da, bu belirsizlik aslında Çin'in denizle ilgili iddialarında kendisine daha esnek bir hareket alanı yaratmaktadır. (O’Rourke, 2014: 15). Aşağıdaki haritada Çin'in hak iddia ettiği U şeklindeki bölge ve tartş̧malı adalar görülmektedir.

Güney Çin Denizi'nde anlaşmazlığa neden olan dört ada grubu bulunmaktadır. Pratas Adaları, Hong Kong'un 200 mil güneyinde yer almakta ve Çin ve Tayvan tarafindan üzerinde hak iddia edilmektedir. Paracel Adaları denizin kuzey kesiminde yer almaktadır ve Vietnam,Çin ve Tayvan tarafindan üzerinde hak iddia edilmektedir. (Çin, Paracel Adaları'nı Vietnam'dan 1974 yılında güç kullanarak almıştır). Scarborough Resifi, Filipinler'in Luzon Adası'na 130 mil uzaklıkta bulunmaktadır ve Çin, Tayvan ve Filipinler tarafindan üzerinde hak iddia edilmektedir.

Son olarak Spratly Adaları, denizin ortasında yer almaktadır ve Çin, Tayvan ve Vietnam adaların tümü üzerinde hak iddia ederken, Malezya, Brunei ve Filipinler adanın bazı kısımları üzerinde hak iddia etmektedirler. (Broderick, 2015: 3). Güney Çin Denizi'ne kıyısı olan devletlerin yanı sıra, bölgede hak iddia etmemekle birlikte, burada çeşitli çıkarları olan dış aktörler olarak tanımlanabilecek devletler vardır. Bölgedeki çatışmaların barışçı yollarla çözümü ve denizlerde dolaşım özgürlüğü üzerine ısrarlarını sürdüren bu devletler ABD, Güney Kore, Japonya, Rusya, Hindistan ve Avustralya'dır. (Ohnesorge, 2016:29).

Çin'in Güney Çin Denizi'ndeki iddialarının en temel dayanağı tarihsel kaynaklardır. Çin'in tarihsel hak iddiasına göre kendi toprakları ve Güney Çin Denizi'ndeki adalar, Mançu Hanedanlığı zamanında Çin'in bir parçası haline gelmiştir ve tüm tarihsel haritalarda ve belgelerde burası Çin'e ait olarak görünmektedir. (Broderick, 2015: 1).

Bölgedeki problem, Çin'in hak iddia ettiği yerlerin, diğer ülkelerin Münhasır Ekonomik Bölge'leriyle (MEB) çakışmasından kaynaklanmaktadır. Münhasır Ekonomik Bölge, BM Deniz Hukuku Sözleşmesi ile kurulmuştur. MEB, devletlerin karasularının ötesinde ve bu karasulara bitişik bölge olup, karasularının ölçülmeye başlandığı esas hatlardan itibaren 200 deniz milinin ötesine uzanmayacak büyüklükteki alandır. (BM Deniz Hukuku Sözleşmesi, Madde 57). 


\section{Harita 1: Güney Çin Denizi Sorunu}

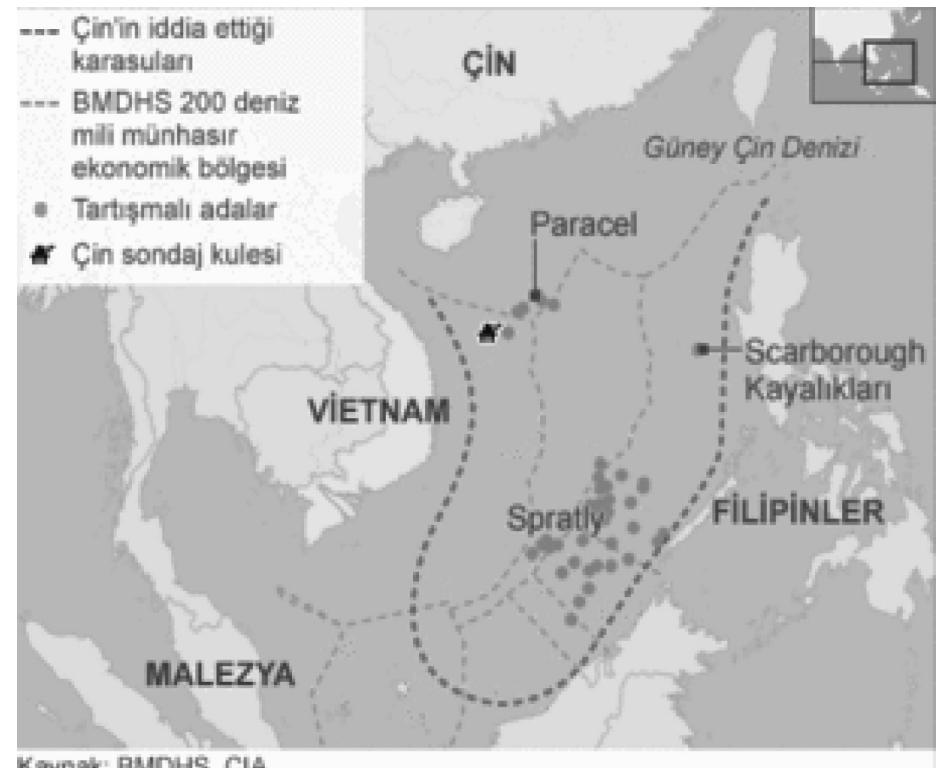

Kaynak: www.bbc.com

4 Kasım 2002'de Çin ve Güney Doğu Asya Uluslar Birliği ${ }^{2}$ (ASEAN- Association of South East Asian Nations) arasında 'Güney Çin Denizi'ne illişkin Tarafların Eylem Bildirisi' imzalanmıştır. Bu bildiriyle taraflar, BM Antlaşması'nın ilkelerine, 1982 BM Deniz Hukuku Sözleşmesi'ne, Güneydoğu Asya'da Dostluk ve İşbirliği Anlaşması'na, Barış İçinde Birarada Yaşamanın Beş illkesi'ne ve uluslararası hukukun tanınmış diğer ilkelerine bağ|ııklarını dile getirmiş; her türlü anlaşmazlığı tehdit veya güç kullanmadan, dostane müzakerelerle ve taraf olan devletlerle, eşitlik ve karşılıkı güven esasıyla çözeceklerini tasdik etmişlerdir. (2002 Declaration). Ancak, bu deklarasyonun bağlayıcı bir niteliğe sahip olmaması nedeniyle bölgede sorunlar devam etmektedir.

Güney Çin Denizi'ndeki tansiyonun artmasından endişe duyan devletlerden biri Amerika Birleşik Devletleri'dir (ABD). Bunun nedeni, Güney Çin Denizi'ne kıyısı olan Filipinler'in, $A B D$ nnin müttefiki olması ve $A B D$ donanması için önemli bir geçiş yolu üzerinde olmasıdır. (Lawrence, 2013). 2010'da ABD Dışişleri Bakanı Hillary Clinton, Güney Çin Denizi'nde dolaşım özgürlüğünün sağlanmasının, ABD’nin ulusal çıkarı olduğunu ifade etmiştir. 2012'de ise bu ulusal çıkarlar, bölgede barış ve istikrarın sağlanması, uluslararası hukuka saygı gösterilmesi, dolaşım özgürlüğü ve engelsiz yasal ticaret olarak genişletilmiştir. (Lawrence, 2013).

Massachusetts Teknoloji Enstitüsü profesörlerinden Fravel'a göre ABD'nin Güney Çin Denizi'nde, erişim/geçiş ve istikrar olmak üzere iki temel çıkarı vardır.

2 ASEAN, 1967'de komünist yayılmaya karşı, Filipinler, Malezya, Tayland, Endonezya ve Singapur'un tarafindan kurulmuştur. 1984'te Brunei, 1995'te Vietnam, 1997'de Lao PDR ve Birmanya ve 1999'da Kamboçya örgüte dahil olmuştur. 
Güney Çin Denizi'ne engelsiz erişim veya geçiş, bölgenin ekonomik dinamizminin sürdürülmesi açısından önemli olmakla birlikte, Güney Çin Denizi'nden Hint Okyanusu'na ve Basra Körfezi'ne geçiş yapan ABD donanmasına ait gemiler nedeniyle ABD'nin askeri gücünü yansıtması açısından da önemlidir. (Fravel, 2014:2).ABD’nin Güney Çin Denizi'ni ulusal çıkarları içerisine kattğı 2010’da, ABD Silahlı Kuvvetleri Pasifik Komutanı Amiral Robert Willard, Çin donanmasının Güney Çin Denizi'ndeki devriyelerini artırdığını ve açık denizler ile tartışmalı ada gruplarında, bölgedeki devletlerin önünü kesmeye daha istekli olduğunu ifade etmiştir. (Zou, 2012: 91). ABD’nin Güney Çin Denizi'ne, hatta daha genel anlamda Asya bölgesine karşı ilgisinin ve endişesinin artmasının altında yatan en önemli neden 'Çin tehdidi' teorisidir. Çin'in ekonomik anlamda hızla büyümesinin yanı sıra, 1992'de Doğu ve Güney Çin Denizleriyle ilgili çıkardığı kanun ${ }^{3}$ ve bu denizlerdeki hak iddiası, Çin'in yayılmacı bir politika izlediği ve bölgede hegemon bir güç olmak istediği şeklinde yorumlanarak 'Çin tehdidi' teorisine zemin hazırlamıştır. (Ateba, 2002). Çin tehdidi teorisi temel olarak; Michigan Üniversitesi profesörlerinden Abramo Fimo Kenneth Organski'nin 1958'de yayınladığı Dünya Politikası (World Politics) adlı kitabındaki 'güç geçişi teorisi'ne (power transition theory) ve neo-realizmin temsilcilerinden John J. Mearshimer'in 'Büyük Güç Politikalarının Trajedisi' (The Tragedy of Great Power Politics) isimli kitabında açıkladığı 'saldırgan realizm' (offensive realism) teorisine dayandırılmaktadır. Güç geçişi teorisine göre; hiyerarşik yapıya sahip olan uluslararası sistemde, statükodan memnun olmayan yükselen güçler, eninde sonunda hegemon güce baş kaldıracaktır. (Organski, 1968). Saldırgan realizme göre ise; bir devletin nihai hedefi, uluslararası sistemde hegemon güç olmaktır. Hayatta kalabilmek için daha fazla güce sahip olma isteği de devletleri saldırganlığa iter. (Mearsheimer, 2001). Dolayısıyla yükselen bir güç olan Çin de, eninde sonunda hegemon güç olmak isteyecek ve statükoya baş kaldıracaktır.

Güney Çin Denizi'ndeki sorunlar değerlendirildiğinde, Çin tehdidi kuramını savunanların iddialarına alt yapı sağladığı söylenebilir. Bu tartş̧malı konularda, Çin tehdidi kuramını savunanlar, donanmasına ve askeri bütçesine ayırdığı miktarın ve denizlerdeki devriye görevi yapan gemi sayısının artmasını Çin'in, güçlendikçe daha saldırgan bir tutum sergilediği şeklinde yorumlarken ${ }^{4}$, örneğin 2002'de Çin ve ASEAN'a üye devletlerin, 'Güney Çin Denizi'nde Tarafların Davranışları Deklarasyonu'nu imzalamasını, Zou Keyuan gibi profesörler, Çin'in sorunu barışçl yollarla çözmek istediğinin bir göstergesi olarak yorumlamaktadırlar. (Zou, 2012: 90). Güney Çin Denizi'nde 'Çin tehdidi' iddiasını güçlendiren bir diğer faktör de, Çin'in burada yapay adalar oluşturmasıdır. ABD, Çin'in bu adaları askeri amaçla kullanacağını iddia ederken, Çin hükümeti bu iddiayı reddetmemekle birlikte adaların deniz araştırmaları, kurtarma, felaketlere karşı önlemler ve meterolojik gözlem gibi kamu yararına kullanılacağını vurgulamıştır. (Glaser, 2015).

3 Çin, 25 Şubat 1992'de "Law on the Territorial Sea and the Contiguous Zone of the People's Republic of China" isimli bir yasa çıkartmıştır. Bu yasaya göre Doğu ve Güney Çin Denizlerindeki adalar Çin'in hakimiyeti altındadir. Daha fazla bilgi için: http://www.un.org/depts/los/LEGISLATIONANDTREATIES/ PDFFILES/CHN_1992_Law.pdf

4 Daha fazla bilgi için bkz.: Jian Zhang, "China's Growing Assertiveness in the South China Sea: A Strategic Shift", National Security College, Australian National University, 2013, http://nsc.anu.edu. au/documents/occasional-5-brief-4.pdf (11.07.2016); Carlyle A. Thayer, "Chinese Assertiveness in the South China Sea and Southeast Asian Responses", Journal of Current Southeast Asian Affairs,Vol:30, No:2, 2011, p.77-104. 
ABD'nin duruma müdahil olması karşısında Çin, sorunun yalnızca bölge devletleri arasında çözülebileceğini savunarak, ABD'nin durumu uluslararasılaştırmasından rahatsızlık duyduğunu her firsatta dile getirmiş ve getirmektedir. (Lawrence, 2013). Kısacası, soruna taraf bazı ülkelerle yakın ilişkileri olan ABD, bölgede artan tansiyondan ve bunun dünya ticareti üzerindeki olası olumsuz etkilerinden rahatsızlık duymakta; Çin ise, giderek soruna daha da müdahil olmaya başlayan ABD'nin, içişlerine karıştğını iddia ederek, bölge devleti olmadığı için soruna müdahil olmaması gerektiğini dile getirmektedir.

Güney Çin Denizi'nde Çin ile en fazla çatışma yaşayan devlet Vietnam'dır. Vietnam, devlete ait petrol şirketi PetroVietnam ile bölgedeki en büyük petrol üreticilerindendir. Vietnam'ın toplam petrol üretimin \%26'sı Güney Çin Denizi'ndeki üç bölgeden sağlanmaktadır ve Vietnam'ın petrol çıkarmak için yeni yer arayışları Çin'le çatışma ihtimalini artırmaktadır. (Buszynski, 2012: 141). Örneğin 2011 yılında iki Çin gözetleme gemisi, Vietnam'ın MEB'inde yer alan, güney sahilinden $120 \mathrm{~km}$ uzaklıkta petrol ve gaz araştırması yapan geminin keşif kablosunu kesmiştir. Ancak Çin Dışişleri Bakanlığı sözcüsü, bunun Çin'in deniz üzerindeki yetki alanına giren tamamen normal bir uygulama olduğunu dile getirmiştir. (Buszynski, 2012: 141). 2012'de Çin ve Vietnam arasında tansiyon yeniden artmış, Vietnam, Paracel ve Spratly adalarını ülkesinin bir parçası sayan ve tüm yabancı gemilerin yetkilileri bilgilendirmesi gerektiğini ifade eden bir yasa çıkarmış ancak Çin bunu yok saymıştı. Vietnam dışında, yine aynı yıl Filipinler'in deniz kuvvetleri, sekiz Çin balıkçı gemisini, yasadışı avlandıkları gerekçesiyle alıkoymuş, bu durum iki ülke arasında iki aylık bir uzaklaşmaya neden olmuştur. (Lunn, 2016:8).

Güney Çin Denizi'ne yönelik; dolaşım özgürlüğü, engelsiz yasal ticaret, bölgede barış ve istikrarın korunması, uçuş serbestliği gibi politikaları olan ABD'nin yanı sıra (Bader, 2014:6), Çin gibi bölgede ekonomik bir güç olarak ön plana çıkan Hindistan da, son dönemlerde Güney Çin Denizi'ndeki gelişmeleri yakından takip etmektedir. Denizde hak iddia eden ülkelerden biri olan Vietnam'ın, son dönemlerde Güney Çin Denizi'nde Hindistan ile ortak petrol arama çalışmaları yapmak istemesi, Çin'in sert tepkisiyle karşılaşmıştr. Aslında Hindistan'ın Vietnam'la bağları, Indira Ganghi dönemine dayanmaktadır. Hindistan'ın 1984 yılında Kamboçya'daki Vietnam destekli hükümeti tanımasından bu yana Vietnam, Hindistan'ı Çin'e karşı bir müttefik olarak görmektedir. (Buszynski, 2012: 142). Vietnam Başbakanı Nguyen Tan Dung, geçtiğimiz 2014 yılında Hindistan'a yapmış olduğu ziyarette, Güney Çin Denizi'yle ilgili olarak, Çin'in konuyu ikili görüşmeler yoluyla çözmek istediğini ve diğer ülkelerin konuya müdahalesine karşı olduğunu, ancak bölgede önemli bir güç olan Hindistan'ın, Güney Çin Denizi'ndeki varlığından oldukça memnun olduklarını ve sorunların barışçı yolla çözümünde önemli bir rolü olacağını ümit ettiklerini ifade etmiştir. (Krishnan ve Boudreau, 2014).

Gerek Vietnam gibi devletlerin Çin'i dengelemek istemesi, gerekse Hindistan'ın bölgedeki kendi ekonomik ve stratejik çıkarları nedeniyle Güney Çin Denizi sorununa müdahil olması, Çin ve Hindistan arasındaki en önemli rekabet konularından biri haline gelmiş ve iki ülke ilişkilerini olumsuz açıdan etkilemeye başlamıştır. 


\section{GÜNEY ÇIN DENIZI SORUNUNUN ÇIN-HINDISTAN ILIŞKILERINE ETKISi}

Güney Çin Denizi, Hindistan için oldukça önemli bir bölgedir. Bunun nedenlerinden biri; Hindistan'ın Japonya ve Güney Kore'yle ticaretinin giderek artması ve önemli bir ticaret yolu olan Güney Çin Denizi'ndeki hareket serbestliğinin, ticaretinin \%25'i Güney Çin Denizi'nden geçen Hindistan için oldukça önemli olmasıdır. ASEAN'la da ticareti 2010-11 yılı itibariyle 57,89 milyar dolara ulaşan Hindistan için, Güney Çin Denizi'nde çıkabilecek her hangi bir çatışma, ekonomik çıkarlarına büyük zarar verecektir. (Majumdar, 2013: 243). Ekonomik boyutun yanı sıra, Güney Çin Denizi'nin Hindistan için stratejik de bir boyutu vardır. Brunel Üniversitesi'nden David Scott'a göre, Çin'in Güney Çin Denizi'ni kontrol altına alması, Çin donanmasını, Hint Okyanusu'na açılan Malakka Boğazı'na getirebilir. Bunun yanı sıra, Batı Pasifik'te ABD ve Japon donanmalarıyla birlikte çalışan Hint donanması için, Güney Çin Denizi'nden güvenli geçiş hakkına sahip olmak büyük önem taşımaktadır. (Scott, 2013: 54). Görüldügü̈ gibi hem ekonomik açıdan hem de stratejik açıdan Güney Çin Denizi Hindistan için kilit bir noktadadır ve gelişmekte olan bir devlet olarak kendi çıkarlarını korumak amacıyla Hindistan, Güney Çin Denizi sorununa müdahil olmaya başlamıştır.

Bunun yanı sıra, dünyanın beşinci büyük donanmasına sahip olan ve ticaretinin $\% 55$ 'lik kısmını Malakka Boğazı yoluyla yapan Hindistan'ın, bu bölgede giderek büyüyen bir donanmaya sahip olması da, başta Çin olmak üzere bazı ülkelerde hoşnutsuzluk yaratmaktadır. (Bajpaee, 2013). Hindistan, 2000 yılında Güney Çin Denizi'ndeki konuşlanmasından sonra, bölgede, insani yardım, felaketzedelere yardım, ortak deniz tatbikatları ve liman ulaştırma istekleri gibi birçok deniz harekâtında yer almıştır. (Bajpaee, 2013). Hindistan'ın Güney Çin Denizi'ndeki varlığı nedeniyle Çin'le tansiyon da zaman zaman artmaktadır. Örneğin, 22 Temmuz 2011'de, Hindistan deniz kuvvetlerine ait bir gemi (INS Airavat), güney Vietnam'daki Nha Trang'a doğru ilerlerken Çin radyo kanalından 'Çin sularından' çıkmaları yönünde uyarılmıştır. Buna karşılık Hindistan Dışişleri Bakanı; Hindistan'ın Güney Çin Denizi de dahil uluslararası sularda hareket serbestliğini desteklediğini ve uluslararası hukukun ilkelerine göre geçiş hakkı olduğunu dile getirmiştir. (Buszynski, 2012: 142). Bunun yanı sıra Çin, Hindistan Petrol ve Doğal Gaz Şirketi'nin (ONGC), Paracel Adaları civarında keşif çalışması yapmasını protesto etmiş, ONGC ise Vietnam'ın iddialarının uluslararası hukuka uygun olduğunu iddia etmiştir. Çin'in tüm karşı çıkmalarına rağmen 12 Ekim 2011'de ONGC ve PetroVietnam arasında petrol ve doğal gaz araması ve üretimiyle ilgili üç yıllık bir işbirliği anlaşması imzalanmıştır. (Buszynski, 2012: 143).

Vietnam, bir önceki başlıkta da ifade edildiği gibi, Çin'i dengelemek amacıyla Hindistan'ı bölgeye çekmek istemektedir. Bu bağlamda Vietnam, Hindistan'ın ortaklık kurduğu en kilit devletlerden biridir. Hindistan ve Vietnam'ın uzun süreli dostluğu 1937 yılında Hindistan Cumhurbaşkanı Jawaharlal Nehru'nun, Ho Chin Minh ile görüşmesiyle başlamıştır. 1947'de bağımsızlığını kazanan Hindistan, Vietnam'ın Fransız işgaline karşı davasını desteklemiş ve iki ülke arasındaki dostluk devam etmiştir. (Sitaraman, 2016: 404). Vietnam ve Hindistan'ın ortak stratejik çıkarları, özellikle de deniz güvenliği ve Çin'in yükselişiyle ilgili endişeler, iki ülkenin giderek yakınlaşmasına neden olmuştur. Hindistan Cumhurbaşkanı Modi, Vietnam'la savunma işbirliğinin en önemli işbirliklerinden biri olduğunu, Hindistan'ın, Vietnam'ın savunma ve güvenlik güçlerinin modernizasyonuna bağlı kalacağını ifade etmiştir. (Silva ve Amorim, 2016: 451). 
Hindistan'ın 2010 yılında Güney Çin Denizi sorununa müdahil olması ve 2011'de Vietnam'la petrol aramak için anlaşma yapması üzerine Çin buna sert bir tepki göstermiştir. Çin medyasından People's Daily gazetesinin editörü konuyla ilgili;

"Hindistan ve Vietnamın ortak petrol arama anlaşması imzalamışlardır. Her iki ülke de bunun Çin için ne anlama geldiğinin farkındadır. Çin, duruşunu göstermek ve Çin'in bölgede önünü kesmeyi amaçlayan bu tür pervasızca davranışları önlemek için çeşitli tedbirler alabilir.... Hindistan'ın Güney Çin Denizi'ne yönelik hırsları vardır. Ancak ulusal gücü henüz bunu başarmaya yetmez.... Hindistan ait olmadığı bir yere burnunu sokmaktadır. Hint toplumu Çin'le şiddetli bir çatş̧maya hazır değildir" şeklinde sert bir yazı kaleme almıştir. ( Naidu, 2015: 23).

Hindistan Cumhurbaşkanı Manmohan Singh ise; Hindistan'ın Güney Çin Denizi'ndeki keşif çalışmalarının yalnızca ticari amaçla olduğunu, deniz üzerindeki hakimiyet konusunun uluslararası hukuka göre çözülmesini gerektiğini ifade etmiştir. (Naidu, 2015: 23).

Çin'in Hindistan'ın Güney Çin Denizi'ndeki varlığından duyduğu rahatsızlığın yanı sıra, Hindistan da Çin'in Güney Çin Denizi'ndeki iddiaları ve Hint Okyanusu'ndaki varlığından endişe duymaktadır. Çin Halk Kurtuluş Ordusu Donanması'nın (PLAN), geçtiğimiz on yıllık süre boyunca Hint Okyanusu Bölgesi'nde korsanlığa karşı konuşlandırdığı gemiler ve 2014 yııının Eylül ayında Sri Lanka'nın Colombo limanına yerleştirdiği Song-sınıf dizel elektrikli denizaltılar, Hindistan'da, Çin tarafindan kuşatıldıklarına dair büyük bir endişeye neden olmuştur. Buna karşılık, Çin'i dengelemek amacıyla Hindistan donanması, Vietnam ve Filipinler gibi dost devletlere düzenli liman ziyaretleri yapmaya başlamıştı. (Sitaraman, 2016: 403).

Hindistan'ın Çin karşısındaki bir diğer müttefiki de ABD'dir. 2014'te Hindistan Cumhurbaşkanı Modi ve ABD Başkanı Obama ortak bir bildiri yayınlamışlardır. Bu bildiride özellikle Güney Çin Denizi'nde deniz güvenliğinin sağlanması, hareket ve uçuş özgürlüğü gibi konularda fikir birliğinde olduklarını ifade etmişlerdir. (Sitaraman, 2016: 406). Ancak Hindistan yine de Çin'i karşısına alacak davranışlardan kaçınmaktadır.

2015'te Modi ve Xi, karşııklı ziyaretlerde bulunmuşlar, Hindistan, Çin'i çevreleme amaçı her hangi bir koalisyona girmeyeceğini ifade etmiştir. (Sitaraman, 2016: 407). Hindistan'da Ulusal Güvenlik Çalışmaları Merkezi'nde profesör olan Bharat Karnad da, bir düşünce kuruluşunda yaptiğı konuşmada, Çin'in Güney Çin Denizi'ndeki provokatif eylemlerine rağmen, $A B D$ ve Hindistan'ın Çin ile olan güçlü ekonomik bağları nedeniyle bu iki ülkenin Çin'e karşı sert eylemlerde bulunmaktan alıkoyduğunu ifade etmiştir. (Grady, 2016).

\section{SONUÇ VE DEĞERLENDIRME}

Çin ve Hindistan, Asya'da büyümekte olan güçler olup, birbirine rakip iki ülkedir. Aralarında uzun yıllardır devam eden sınır problemleri, Çin'in Pakistan'la yakın ilişkileri ve Tibet sorunu iki ülkenin başlıca problemleridir. Bunun yanı sıra her ne kadar Çin, Hindistan'ın başlıca ticaret ortağına haline gelmişse de, Hindistan aleyhine giderek artan ticaret açığı, iki ülke arasındaki bir diğer problemdir. Son yıllarda ise gelişmekte olan bu iki ülkenin enerji ihtiyacının artması, onları yeni arayışlara itmiştir. Bu bağlamda Güney Çin Denizi iki ülke için yeni bir rekabet alanı haline gelmiştir. 


\section{International Journal of Social Sciences}

Çin, Tayvan, Vietnam, Kamboçya, Filipinler, Malezya ve Brunei'in Güney Çin Denizi sorununda farklı ve birbiriyle çatışan hak iddiaları yüzünden, bölgede durum belirsizliğini korumakta ve uluslararası hukuk açısından sorunu oldukça karmaşık bir hale getirmektedir. Diğer yandan ekonomisi giderek büyüyen Hindistan'ın, Doğu Asya'daki stratejik önemi de giderek artmakta ve ticaretinin büyük kısmı Malakka Boğazı'ndan geçtiği için, Güney Çin Denizi'nde Çin'in hak iddiaları ve varolan anlaşmazlıklar, Hindistan'ı yakından ilgilendirmektedir. Vietnam başta olmak üzere, diğer Güneydoğu Asya devletleri de Çin'i dengelemek açısından Hindistan'ı bu bölgeye çekmek istemekte ve bölgede, denizlerle ilgili yeni bir yapılanmaya gitmek istemektedirler.

Bilindiği gibi Çin, 'uyumlu dünya' ilkesi kapsamında barış, işbirliği ve gelişime vurgu yapmakta ve özellikle kendi içinde bulunduğu bölgeden başlayarak, bu amacını tüm dünyada gerçekleştirmek istemektedir. Güneydoğu Asya uzmanlarından profesör Carlyle A. Thayer'a göre, Çin'in ekonomik gelişim hedefini ön plana koyması, enerji kaynaklarına olan talebi artırmakta, bu da enerji güvenliği için önemli deniz yollarının güvenli kalmasını gerektirmektedir. (Thayer, 2010:70). Bu açıdan bakıldı̆̆ında, Çin'in, sorunları barışçıl yollardan çözmek istemekle birlikte, kendi ulusal güvenliğine zarar verebilecek konularda çok daha sert adımlar atabileceği söylenebilir. Bu bağlamda Güney Çin Denizi'ndeki anlaşmazlığın çözümüne bir katkı sağlamamakla birlikte, Hindistan'ın konuya müdahil oluşu, Çin'e karşı bölgede dengeleyici bir unsur olabilir.

Sonuç olarak, Hindistan her ne kadar aralarındaki ekonomik bağlar nedeniyle Çin'i doğrudan hedef alan ya da çevrelemeye çalışan politikalara karşı olduğunu ifade etse de, Güney Çin Denizi ve Hindistan'ın konuya müdahil oluşu, iki ülke arasındaki ilişkilerde olumsuz yönde bir durum teşkil edecektir denilebilir. 


\section{KAYNAKÇA}

2002 Declaration on the Conduct of Parties in the South China Sea, ASEAN, http://asean. org/?static_post=declaration-on-the-conduct-of-parties-in-the-south-china-sea-2 (17.06.2016).

Agreement Between the Republic of India and The People's Republic of China on Trade and Intercourse Between Tibet Region of China and India, Anlaşmanın tam metni için bkz. http://treaties.un.org/doc/publication/ unts/volume\%20299/v299.pdf (01.07.2016)

Arif, S. M. (2013). A History of Sino-Indian Relations: From Conflict to Cooperation. International Journal of Political Science and Development, Vol.1, no.4, 129-137.

Ateba, B. (2002). Is the Rise of China a Security Threat? Polis, Vol.9, Numero Special.

Bader, J., Lieberthal,K., ve McDevitt, M. (2014). Keeping the South China Sea in Perspective. The Foreign Policy Brief, Brookings.

Bajpaee, C. (2013). Reaffirming India's South China Sea Credentials. August 14, The Diplomat, $\mathrm{http}: / /$ thediplomat.com/2013/08/reaffirming-indias-south-china-sea-credentials/ (04.07.2016)

Birleşmiş Milletler Deniz Hukuku Sözleşmesi. (1982). http://denizmevzuat.udhb.gov.tr/ dosyam/denizhukuku.pdf (17.06.2016).

Broderick, K. (2015). Chinese Activities in the South China Sea: Implications for the American Pivot to Asia. Project 2049 Institute.

Burke, J. (2014). India and China Announced Trade Deals During Xi Visit to Delhi. The Guardian, http://www.theguardian.com/world/2014/sep/18/india-china-tradedeals-xi-delhi (01.07.2016)

Buszynski, L. (2012). The South China Sea: Oil, Maritime Claims, and US- China Strategic Rivalry. The Washington Quarterly, Vol.35, No.2, 139-156.

Cheng, R. (2010). Sino-Indian Relations:Sixty Years of Experience and Enlightenment. IPCS Special Report, 91, Institute of Peace and Conflict Studies, 1-10.

China-India Trade Relations, Business Maps of India, http://business.mapsofindia.com/ trade-relations/india-china/ (01.07.2016)

Economy Watch. (2010). China's Economic Relations. http://www.economywatch.com/ international-economic-relations/ch (02.07.2016).

Embassy of India. (2016). Economic and Trade Relations. http://www.indianembassy.org.cn/ DynamicContent. aspx?Menuld=97\&SubMenuld=0 (02.07.2016)

Fravel, M. T. (2014). US Policy Towards the Disputes in the South China Sea Since 1995. Policy Report, S. Rajaratnam School of International Studies, 1-10.

Glaser, B.S. (2015). The Growing Militarisation of the South China Sea. 29.07.2015, The Interpreter, http://www.lowyinterpreter.org/post/2015/07/29/The-growingmilitarisation-of-the-South-China-Sea.aspx (25.08.2015)

Grady, J. (2016). Expert: India, US Relationship with China Make 'Hard Actions' Difficult in South China Sea, Indian Ocean. 25 May, USNI News, https://news.usni. org/2016/05/25/expert-india-u-s-relationship-china-make-hard-actions-difficultsouth-china-sea-indian-ocean (11.07.2016). 
India-China Bilateral Relations, Embassy of India in Beijing, China, http://www. indianembassy.org.cn/DynamicContent. aspx? Menuld=3\&SubMenuld $=0$ (01.07.2016)

Jian, Z. (2013). China's Growing Assertiveness in the South China Sea: A Strategic Shift. National Security College, Australian National University, http://nsc.anu.edu.au/ documents/occasional-5-brief-4.pdf (22.07.2015)

Kissinger, H. (2012). On China, Penguin Books.

Krishnan, U.; John . (2014). Vietnam Seeks India Role in China Sea as Dung Meets Modi. October 28, Bloomberg News, http://www.bloomberg.com/news/201410-28/vietnam-seeks-india-role-in-china-sea-spat-as-dung-meets-modi.html (04.07.2016)

Lawrence, S. V. (2013). US-China Relations: An Overview of Policy Issues. CRS Report for Congress, Congressional Research Service, August 1, https://fas.org/sgp/crs/row/ R41108.pdf (04.07.2016)

Lunn, J. (2016). The South China Sea Dispute: January 2016 Update. House of Commons Library

Majumdar, M. (2013). India's Stakes in the South China Sea. International Journal of Humanities and Social Science, Vol.3, No.13, 242-247.

Mearsheimer, J. (2001). The Tragedy of Great Power Politics, New York: Norton.

Ministry of External Affairs. (2012). Government of India,"India-China Bilateral Relations", https://mea.gov.in/Portal/ForeignRelation/China-January-2012.pdf (01.07.2016).

Mitchell, D. J.; Bajpaee, C. (2007). China and India. in The China Balance Sheet 2007 and Beyond, (eds. C. Fred Bergsten, Bates Gill, Nicholas R. Lardy and Derek Mitchell), Washington D.C., Center for Strategic and International Studies and Peter G. Peterson Institute for International Economics, 151-70.

Naidu, G.V.C. (2015). India, China and East Asia. in India and China in the Emerging Dynamics of Asia, (eds.G.V.C. Naidu, Mumin Chen, Raviprasad Narayanan ), Springer, 9-25.

O'Rourke, R. (2014). Maritime Territorial and Exclusive Economic Zone (EEZ) Disputes Involving China: Issues for Congress, Congressional Research Service, September 26.

Ohnesorge, H. W. (2016). A Sea of Troubles: International Law and the Spitsbergen Plus Approach to Conflict Management in the South China Sea. in Power Politics in Asia's Contested Waters: Territorial Disputes in the South China Sea, (eds. Enrico Fels and Truong-Minh Vu), Springer International Publishing.

Organski, A.F.K. (1968). World Politics. Alfred A Knopf, 2nd edition.

Panda, A. (2014). India Considers China Import Duties. October 15, The Diplomat, http:// thediplomat.com/2014/10/india-considers-china-import-duties/ (01.07.2016)

Scott, D. (2013). India's Role in the South China Sea: Geopolitics and Geoeconomics in Play. India Review, Vol.12, No.2, 51-69.

Silva, A. H. L.; ve de Amorim, W. D. (2016). Australia, India and Japan: The Three 'Worried Outsiders' and Their Strategies Towards the South China Sea. in Power Politics in 
Asia's Contested Waters: Territorial Disputes in the South China Sea, (eds.Enrico Fels and Truong-Minh Vu), Springer International Publishing.

Sitaraman, S. (2016). Rising Chinese Power and Territorial Assertiveness in the South China Sea: India-Vietnam Strategic Partnership as a Counterbalancing Endeavor. in Power Politics in Asia's Contested Waters: Territorial Disputes in the South China Sea, (eds. Enrico Fels and Truong-Minh Vu), Springer International Publishing.

Thayer, C. A. (2010). The United States and Chinese Assertiveness in the South China Sea. Security Challenges, Vol.6, No.2, 69-84.

Thayer, C. A. (2011). Chinese Assertiveness in the South China Sea and Southeast Asian Responses. Journal of Current Southeast Asian Affairs, Vol.30, No.2, 77-104.

Zou, K. (2012). Building a 'Harmonious World': A Mission Impossible. The Copenhagen Journal of Asian Studies, Vol.30, No.2, 74-99. 